\title{
GABAERGIC SYNAPTIC TRANSMISSION ONTO STRIATAL CHOLINERGIC INTERNEURONS IN DOPAMINE D2 RECEPTOR KNOCK-OUT MICE
}

\section{ASAKO SATO ${ }^{1,2}$, TOSHIKUNI SASAOKA ${ }^{1,2,3}$, TAKUMA NISHIJO ${ }^{4,5}$ AND TOSHIHIKO MOMIYAMA ${ }^{4}$}

${ }^{1}$ Department of Laboratory Animal Science, Kitasato University School of Medicine, Sagamihara 252-0374, Japan, ${ }^{2}$ National Institute for Basic Biology, Okazaki 444-8585, Japan, ${ }^{3}$ Department of Comparative and Experimental Medicine, Center for Bioresource-based Researches, Brain Research Institute, Niigata University, Niigata 951-8585, Japan, ${ }^{4}$ Department of Pharmacology, Jikei University School of Medicine, Tokyo 105-8461, Japan, ${ }^{5}$ Department of Pharmacology, Keio University Faculty of Pharmacy, Tokyo 105-8512, Japan

Correspondence should be addressed to Toshihiko Momiyama Department of Pharmacology, Jikei University School of Medicine, Tokyo 105-8461, Japan, tmomi@jikei.ac.jp

Running title: Striatal GABAergic synapse in D2R KO mice 


\section{Abstract}

Whole-cell or cell-attached analysis was carried out in dopamine (DA) D2 receptor (D2R) knock-out (KO) mice to elucidate the function of this receptor in the regulation of GABAergic synaptic transmission onto striatal cholinergic interneurons as well as their spontaneous firing. In slice preparation obtained from wild type mice, evoked GABAergic inhibitory postsynaptic currents (IPSCs) showed frequency-dependent suppression, and this suppression significantly decreased in the presence of a D2-like receptor antagonist or in D2R KO mice. Contribution of N-type calcium channel was also significantly reduced in the striatal cholinergic interneurons of the D2R KO mice compared with that in the wild type mice. Spontaneous firing of striatal cholinergic interneurons was inhibited by 5 or $10 \mathrm{~Hz}$ stimulation, and the suppression was decreased in the presence of a D2-like receptor antagonist or in D2R KO mice. These findings substantiate the physiological role of D2R in the regulation of GABAergic synaptic transmission onto striatal cholinergic interneurons as well as their excitability, confirming the tight coupling between D2R and N-type calcium channels in the regulation of GABA release.

Key words: dopamine receptors, GABAergic synapse, knock-out mice, striatum, cholinergic neuron 


\section{INTRODUCTION}

Dopaminergic neurons in the substantia nigra pars compacta (SNc) send their axons to medium spiny neurons as well as cholinergic interneurons in the striatum (Freund et al., 1984;

Kubota et al., 1987), regulating neuronal activities of these striatal neurons. Nigro-striatal dopaminergic pathway plays important roles in motor control (for review, Kreitzer and Malenka, 2008) through the interaction between dopamine (DA) and acetylcholine (ACh) (for review, Crag, 2006; Pisani et al., 2007). One of the potential neurophysiological events contributing to the motor control is synaptic transmission in the striatum (for review, Calabresi et al., 2007). However, little information has been available on the DA receptor subtypes contributing to the synaptic transmission. In cellular levels, the roles of dopamine and/or DA receptors in striatal medium spiny neurons are still multifaceted; both excitatory and inhibitory effects have been reported (for review, Surmeier et al., 2007). On the other hand, in cholinergic interneurons, activation of postsynaptic D1-like receptors depolarizes the membrane by closing potassium channels or opening non-selective cation channels (Aosaki et al., 1998), whereas activation of presynaptic D2-like receptors located on GABAergic terminals inhibits GABA release onto cholinergic interneurons (Pisani et al., 2000; Momiyama and Koga, 2001) by selectively blocking N-type calcium channels (Momiyama and Koga, 2001). These previous findings raise the question regarding the role of physiologically released DA, as well as on the physiological linkage between DA receptors 
and N-type calcium channels.

Using the D2R knock out (D2R KO) mice, we examined (1) the effect of stimulus frequency on GABAergic transmission onto striatal cholinergic interneurons as well as on their spontaneous firing in order to determine the physiological role of endogenously released DA, and (2) the physiological linkage between dopamine D2 receptors (D2R) and N-type calcium channels in the modulation GABA release.

\section{EXPERIMENTAL PROCEDURES}

Animal handling and all experimental procedures were done according to the Guiding Principles for the Care and Use of Animals in the Field of Physiological Sciences of the Physiological Society of Japan (2009), the UK Animals (Scientific Procedures) Act 1986, and

the guidelines of the National Institutes of Natural Sciences, Jikei University School of Medicine and Kitasato University. These procedures were approved by the Animal Care and Use Committee of the National Institutes of Natural Sciences, Jikei University School of Medicine and Kitasato University School of Medicine.

\section{Dopamine receptor deficient mice}

Mice lacking D2R were generated according to the protocol by Katsuki and colleagues (Yamaguchi et al., 1996) and backcrossed for up to ten generations with C57BL/6J mice. 
Genotypes were determined by PCR analysis of genomic DNA extracted from each mouse’s tail. Mice were kept in stable conditions of temperature $22 \pm 2{ }^{\circ} \mathrm{C}$ and humidity $55 \pm 5 \%$ with a 12 hr light-dark cycle.

\section{Slice preparation}

Mice (postnatal 20-23 or 35-44 days) were decapitated under deep halothane anesthesia, and coronal slices containing the striatum were cut (300 $\mu \mathrm{m}$ thick) using a microslicer (PRO7, Dosaka, Kyoto, Japan) in ice-cold oxygenated cutting Krebs solution of the following composition (mM): choline chloride, $120 ; \mathrm{KCl}, 2.5 ; \mathrm{CaCl}_{2}, 0.5 ; \mathrm{MgCl}_{2}, 7 ; \mathrm{NaH}_{2} \mathrm{PO}_{4}, 1.25$; $\mathrm{NaHCO}_{3}$, 26; D-glucose, 15; ascorbic acid, 1.3. The slices were then transferred to a holding chamber containing standard Krebs solution of the following composition (mM): $\mathrm{NaCl}, 124$;

$\mathrm{KCl}, 3 ; \mathrm{CaCl}_{2}, 2.4 ; \mathrm{MgCl}_{2}, 1.2 ; \mathrm{NaH}_{2} \mathrm{PO}_{4}, 1 ; \mathrm{NaHCO}_{3}, 26 ;$ D-glucose, 10; $\mathrm{pH} 7.4$ when bubbled with $95 \% \mathrm{O}_{2}-5 \% \mathrm{CO}_{2}$. Slices were incubated in the holding chamber at room temperature $\left(21-26{ }^{\circ} \mathrm{C}\right)$ for at least $1 \mathrm{~h}$ before recording.

\section{Recording and data analysis}

For recording, a slice was transferred to the recording chamber, held submerged, and superfused with standard Krebs solution (bubbled with $95 \% \mathrm{O}_{2}-5 \% \mathrm{CO}_{2}$ ) at a rate of 3-4 ml

$\min ^{-1}$. Neurons within the striatum were visually identified with a $60 \mathrm{x}$ water immersion 
objective attached to an upright microscope (BX50WI, Olympus Optics, Tokyo, Japan). Images were detected with a cooled CCD camera (CCD-300T-RC, Nippon Roper, Japan) and displayed on a video monitor (LC-150M1, SHARP, Japan). Pipettes for whole-cell recordings were made from standard-walled borosilicate glass capillaries (1.5 mm outer diameter; Clark Electromedical, Reading, UK). For synaptic currents recordings, patch pipettes were filled with a CsCl-based internal solution of the following composition (mM): $\mathrm{CsCl}, 140 ; \mathrm{NaCl}$, 9; Cs-EGTA, 1; Cs-HEPES, 10, Mg-ATP, 2 (pH adjusted with 1M CsOH). For current-clamp recordings, a K-gluconate-based internal solution of the following composition (mM) was used: K-gluconate, 120; $\mathrm{NaCl}$, 6; $\mathrm{CaCl}_{2}$, 5; $\mathrm{MgCl}_{2}$, 2; K-EGTA, 0.2; K-HEPES, 10; Mg-ATP,


identified cholinergic interneurons within the striatum using a patch-clamp amplifier (Axopatch 200B, Molecular Devices, Foster City, CA, USA). The series resistance was measured from the amplifier, and the data were discarded, if the series resistance changed by more than $10 \%$ of the initial value. The access resistance was monitored by measuring capacitative transients obtained in response to a hyperpolarizing voltage step ( $5 \mathrm{mV}, 25 \mathrm{~ms}$ ) from a holding potential of $-60 \mathrm{mV}$. No correction was made for the liquid junction potentials (calculated to be $5.0 \mathrm{mV}$ by pCLAMP7 software, Molecular Devices). Synaptic currents were evoked by extracellularly delivered voltage pulses (0.2-0.4 ms in duration) of suprathreshold intensity via a stimulating electrode filled with $1 \mathrm{M} \mathrm{NaCl}$. The stimulating electrode was 
placed within 50-120 $\mu \mathrm{m}$ radius of the recorded neuron. The position of the stimulating electrode was varied until a stable response was evoked in the recorded neuron. All the inhibitory postsynaptic currents (IPSCs) were evoked at a holding potential of $-60 \mathrm{mV}$. Experiments were carried out at room temperature $\left(21-26^{\circ} \mathrm{C}\right)$.

Data were stored on digital-audio tapes using a DAT recorder (SONY, Japan, DC to 10 $\mathrm{kHz}$ ). Synaptic currents were digitized off-line at $10 \mathrm{kHz}$ (low-pass filtered at $2 \mathrm{kHz}$ with an 8-pole Bessel filter) using pCLAMP9 software (Molecular Devices). The effects of drugs on the evoked IPSCs were assessed by averaging their amplitudes for $100 \mathrm{~s}$ (20 traces) after the effect had reached the steady state and comparing this value with the averaged amplitude of 20 traces just before the drug application. Statistical analysis was carried out using both Student's $t$ test (two-tailed) and a non-parametrical Mann-Whitney $U$ test. P value of 0.05 was used as the confidence limit and data are expressed as mean \pm S.E.M.

\section{Drugs}

Synthetic blocker of N-type calcium channel, $\omega$-conotoxin GVIA ( $\omega$-CgTX), and synthetic blocker of P/Q-type calcium channel, $\omega$-agatoxin TK ( $\omega$-Aga-TK) were purchased from

Alamone labs (Jerusalem, Israel). These toxins were dissolved in oxygenated perfusing solution containing cytochrome $c\left(1 \mathrm{mg} \mathrm{ml}^{-1}\right.$, Sigma). Other drugs were stored as frozen stock solutions and dissolved in the perfusing solution just before application in the final 
concentration indicated. Bicuculline methochloride, 6-Cyano-7-nitroquinoxalline-2,3-dione (CNQX), D-(-)-2-amino-5-phosphonopentanoic acid (D-AP5) from Tocris Cookson (Bristol,

UK). Trans-(-)- 4aR- 4,4a,5,6,7,8,8a,9- octahydro-5- propyl-1H-pyrazolo[3,4-g]quinoline hydrochloride (quinpirole) and S(-)-5-aminosulfonyl -N-[(1-ethyl-2-pyrrolidinyl)-methyl] -2-methoxybenzamide (sulpiride) were from Research Biochemicals International (Natic, MA). Strychnine was from Sigma (St Louis, MO, USA). All drugs were bath applied.

\section{RESULTS}

\section{Identification of striatal interneurons in mice}

Whole-cell recordings were made from 82 (45 in wild type mice and 37 in D2R KO mice) cholinergic interneurons within the striatum, identified visually and electrophysiologically. Neurons in the striatum were viewed with a microscope fitted with a water-immersion optic (Nikon, Tokyo, Japan or Olympus BX50WI, Olympus, Tokyo, Japan). Only those within the dorsal part of the striatum were used in the present study, similarly to the previous study in rats (Momiyama and Koga, 2001). Large neurons (the long axis $>30 \mu \mathrm{m}$, Fig. 1A) were selected for whole-cell recording according to the size distribution of cholinergic and non-cholinergic neurons in the striata of rats (Kawaguchi, 1992) or mice (Govindaiah et al., 2010). In order to functionally identify striatal cholinergic neurons, membrane properties of these large cells were also examined using a K-gluconate-based internal solution (Fig. 1B). 
When hyperpolarizing current pulses were applied through the recording pipette containing $\mathrm{K}^{+}$-based internal solution under the current-clamp mode, these neurons exhibited a characteristic voltage sag during a large hyperpolarization (Fig. 1B), similarly to the previous studies using rats (Jiang and North, 1991; Kawaguchi, 1992; Kawaguchi et al., 1995; Aosaki et al., 1998) or mice (Govindaiah et al., 2010). The voltage sag was also observed with $\mathrm{Cs}^{+}$-based internal solution to block the inwardly-rectifying $\mathrm{K}^{+}$conductance, similarly to the case in rats (Momiyama and Koga, 2001) or mice (Govindaiah et al., 2010). Therefore, large neurons that exhibited a characteristic voltage sag during a large hyperpolarization were used for the present study.

\section{GABAergic synaptic transmission}

Synaptic currents were evoked at a holding potential of $-60 \mathrm{mV}$ by focal stimulation in the presence of CNQX (5 $\mu \mathrm{M})$, D-AP5 $(25 \mu \mathrm{M})$ and strychnine $(0.5 \mu \mathrm{M})$ to block glutamatergic and glycinergic components (Fig. 1C). The evoked currents were reversibly blocked by bath application of bicuculline (10 $\mu \mathrm{M}$, Fig. 1C) in all of 6 neurons examined, confirming that they are $\mathrm{GABA}_{\mathrm{A}}$ receptor-mediated inhibitory postsynaptic currents (IPSCs) in nature, similar to

our previous study in rats (Momiyama and Koga, 2001). Thus in the rest of the study, GABAergic IPSCs were pharmacologically isolated using the same combination of blockers.

IPSC amplitude evoked at $0.2 \mathrm{~Hz}$ in wild type and D2R KO mice was $-272.6 \pm 25.7 \mathrm{pA}$ 
( $\mathrm{n}=41)$ and $-212.8 \pm 24.3 \mathrm{pA}(\mathrm{n}=27)$, respectively. The difference between these two values was not significantly different $(\mathrm{P}>0.05)$.

\section{Selective coupling of $\mathrm{D} 2$ receptors with $\mathrm{N}$-type calcium channels}

In wild type mice, bath application of quinpirole, a dopamine D2-like receptor agonist, at a concentration of $30 \mu \mathrm{M}$ inhibited the evoked IPSCs in a reversible manner (Fig. 2A), similarly to the previous studies in rats (Pisani et al., 2000; Momiyama and Koga, 2001). On the other hand, quinpirole had little or no effect on the IPSCs in D2R KO mice (Fig. 2B). Quinpirole-induced inhibition of IPSC amplitude in wild type and D2R KO mice was $32.9 \pm$ $2.24 \%(n=4)$ and $3.28 \pm 1.38 \%(n=6)$, respectively (Fig. 2C).

Bath application of an N-type calcium channel blocker, $\omega$-CgTX (3 $\mu \mathrm{M})$ caused a gradual decline in the amplitude of IPSCs, reaching a steady-state in 5-10 min in wild type mice (Fig. 2A). The degree of suppression by $\omega$-CgTX was $58.6 \pm 1.97 \%(n=6$, Fig. 5A and $\mathrm{C})$, comparable to that in rats (Momiyama and Koga, 2001). After confirming quinpirole (30 $\mu \mathrm{M})$-induced inhibition had showed complete recovery following washout, $\omega$-CgTX (3 $\mu \mathrm{M})$ was applied, and after $\omega$-CgTX's effect had reached a steady-state, quinpirole (30 $\mu \mathrm{M})$ was applied again. Quinpirole no longer suppressed IPSCs in the presence of $\omega$-CgTX (2.07 \pm $0.53 \%$ inhibition, n=4, Fig. 2A and 2C). These results indicate that the inhibitory action of quinpirole was selectively coupled to presynaptic N-type calcium channels, confirming the 
selective coupling between D2-like receptors and N-type calcium channels suggested in our previous study using rats (Momiyama and Koga, 2001).

\section{Frequency-dependent suppression of IPSCs}

Inhibition of IPSCs evoked in striatal cholinergic interneurons by exogenously applied quinpirole, a D2-like receptor agonist, raises the question of the modulatory roles of DA physiologically released in the striatum, since dopaminergic axons originated from dopaminergic neurons in the substantia nigra pars compacta terminate in striatal cholinergic interneurons (Kubota et al., 1987). To address the question, dependency of the evoked IPSCs on the stimulus-frequency was examined between 0.2 and $10 \mathrm{~Hz}$. Mean IPSCs were collected once IPSC amplitude had reached steady state during sustained stimulation (Silver et al., 1998). IPSC amplitude at each stimulus frequency was judged by visual inspection that it had reached steady state. At $0.5-2 \mathrm{~Hz}$, the amplitude reached steady state within $1 \mathrm{~min}$. At 3.3, 5, or $10 \mathrm{~Hz}$, it reached steady state within 10-20 s. IPSC amplitude at each stimulus frequency returned to the basal level within several seconds after the stimulus frequency was returned to $0.2 \mathrm{~Hz}$, and the duration of recovery to the basal level could correspond to the duration of D2-like receptor mediated slow synaptic potential evoked in midbrain dopaminergic neurons (Beckstead et al., 2004). IPSCs evoked in striatal cholinergic interneurons of wild type mice showed frequency-dependent suppression during sustained stimulation. This is illustrated in 
Figure 3A, which shows averaged IPSCs obtained at various stimulus frequencies $(0.2-10 \mathrm{~Hz})$ under steady state conditions. The relationship between IPSC peak amplitude and stimulus frequency is shown in Figure 3B. In these series of experiments, the averaged IPSC amplitude in wild type mice evoked at $0.2 \mathrm{~Hz}$ was $-266.3 \pm 43.3 \mathrm{pA}(\mathrm{n}=16)$. The amplitude evoked at 0.5, 1, 2, 3.3, 5 and $10 \mathrm{~Hz}$ was $0.80 \pm 0.01(\mathrm{n}=16), 0.72 \pm 0.03(\mathrm{n}=16), 0.51 \pm 0.04(\mathrm{n}=14)$, $0.50 \pm 0.04(\mathrm{n}=6), 0.38 \pm 0.02(\mathrm{n}=12)$ and $0.19 \pm 0.01(\mathrm{n}=12)$ as a fraction of the corresponding neurons’ IPSC amplitude at $0.2 \mathrm{~Hz}$, respectively (Fig. 3B, open circles). In order to clarify the receptors involving frequency-dependent suppression of IPSCs, the effect of sulpiride, a D2-like receptor antagonist, was examined on the frequency dependent inhibition of IPSCs in wild type mice. After 10 min perfusion of external solution containing sulpiride at a concentration of $10 \mu \mathrm{M}$, the same frequent-dependency was examined. IPSC amplitude in wild type mice evoked at $0.5,1,2,5$ and $10 \mathrm{~Hz}$ in the presence of sulpiride was $0.90 \pm 0.06(n=6), 0.79 \pm 0.03(n=6), 0.58 \pm 0.02(n=6), 0.51 \pm 0.02(n=6)$ and $0.32 \pm 0.06$ $(n=6)$, respectively (Fig. 3B, open squares). The difference between in the absence and presence of sulpiride was significant $(\mathrm{P}<0.05)$ in IPSC amplitude evoked at 5 and $10 \mathrm{~Hz}$. The weak inhibition in the presence of sulpiride was not significant $(\mathrm{P}>0.05)$ at lower frequencies. When the effect of sulpiride was compared between the corresponding 6 neurons, the difference was significant $(\mathrm{P}<0.05)$ only at $10 \mathrm{~Hz}$.

In terms of specificity for the receptor subtypes, utilization of receptor knock out mice is a 
better tool than pharmacological manipulation. Therefore, frequency-dependent suppression of IPSCs was examined in dopamine D2R KO mice. In these series of experiments, the averaged IPSC amplitude in D2R KO mice evoked at $0.2 \mathrm{~Hz}$ was $-262.9 \pm 56.7 \mathrm{pA}(\mathrm{n}=7)$. As shown in Figures 3A and 3B, frequency-dependent suppression of IPSCs was reduced in D2R KO mice, and the reduction was apparently larger than that observed in wild type mice with sulpiride. The IPSC amplitude in D2R KO mice at the frequency of 0.5, 1, 2, 3.3, 5 and $10 \mathrm{~Hz}$ was $0.99 \pm 0.01(n=7), 0.91 \pm 0.02(n=7), 0.84 \pm 0.07(n=7), 0.87 \pm 0.01(n=5), 0.62 \pm$ $0.06(n=7)$ and $0.44 \pm 0.05(n=7)$, respectively as a fraction of that at $0.2 \mathrm{~Hz}$ (Fig. 3B, closed circles). The value in D2R KO mice was significantly $(\mathrm{P}<0.05)$ different from that in wild type mice at each of the corresponding stimulus frequency.

\section{High frequency stimulation-induced effect on the firing of cholinergic interneurons}

Frequency-dependent suppression and its reduction in D2R KO mice as well as in the presence of sulpiride indicate endogenous release of DA with high frequency stimulation might be involved in this suppression. A previous study has reported D2-like receptor agonist-induced modulation of firing frequency of cholinergic interneurons (Maurice et al., 2004). Therefore, effects of high frequency stimulation (5 and $10 \mathrm{~Hz}$ ), that mimic the spontaneous firing rate of dopaminergic neurons in the midbrain (Beckstead et al., 2004), on

the spontaneous firing of cholinergic interneurons was examined, using cell-attached 
recording technique with K-gluconate pipette solution. The site and intensity of stimulation was similar to that in the case of evoked IPSCs.

Spontaneous firing rate with cell-attached recording of cholinergic interneurons in slices obtained from wild type mice and D2R KO mice was $5.67 \pm 0.94 \mathrm{~Hz}(\mathrm{n}=6)$ and $5.13 \pm 0.26$ $\mathrm{Hz}(\mathrm{n}=6)$, respectively. Similar stimulating protocol was applied to that used in the suppression of IPSCs; $15 \mathrm{~s}$ stimulation at $5 \mathrm{~Hz}$ and $10 \mathrm{~s}$ stimulation at $10 \mathrm{~Hz}$. Mean firing rate was calculated just before and after the stimulation. In wild type mice, firing rate was reduced to $3.45 \pm 0.64$ and $2.85 \pm 0.57 \mathrm{~Hz}$ (each $\mathrm{n}=6$ ) after 5 and $10 \mathrm{~Hz}$ stimulation, respectively (Fig. 4A and C), similar to the case of agonist activation of D2-like receptors (Maurice et al., 2004). Similar to the case of evoked IPSCs, stimulation-induced inhibition of firing was recovered to the basal level within $10 \mathrm{~s}$ after the cessation of stimulation. After the recovery of stimulation-induced inhibition of firing, sulpiride, a D2-like receptor antagonist at a concentration of $10 \mu \mathrm{M}$ was applied in the bath for 5-10 min, and stimulation was again applied in the presence of sulpiride. Firing rate in the presence of sulpiride was $5.71 \pm 1.15$ $\mathrm{Hz}$, which was not significantly $(\mathrm{P}<0.05)$ from control $(5.67 \pm 0.94 \mathrm{~Hz}, \mathrm{n}=6)$. Stimulation induced inhibition of firing was antagonized in the presence of sulpiride. In the presence of sulpiride, the firing rate after 5 and $10 \mathrm{~Hz}$ stimulation was $5.34 \pm 1.15 \mathrm{~Hz}(\mathrm{n}=6)$ and $5.21 \pm$ $1.16 \mathrm{~Hz}(\mathrm{n}=6)$, respectively, significantly $(\mathrm{P}<0.05)$ larger than that without sulpiride (Fig. 4A and C). Spontaneous firing rate of cholinergic interneurons in slices from D2R KO mice was 
$5.13 \pm 0.26 \mathrm{~Hz}(\mathrm{n}=6)$, which was not significantly different $(\mathrm{P}>0.05)$ from that of wild type mice $(5.67 \pm 0.94 \mathrm{~Hz}, \mathrm{n}=6)$. In D2R KO mice, 5 and $10 \mathrm{~Hz}$ stimulation had no significant (P>0.05) effect on the firing rate (Fig. 4B). Firing rate after 5 and $10 \mathrm{~Hz}$ stimulation was 5.40 $\pm 0.33 \mathrm{~Hz}(\mathrm{n}=6)$ and $5.49 \pm 0.43 \mathrm{~Hz}(\mathrm{n}=6)$, respectively, which was not significantly $(\mathrm{P}>0.05)$ different from the value before stimulation $(5.13 \pm 0.26 \mathrm{~Hz}, \mathrm{n}=6$, Fig, 4C).

\section{Contribution of calcium channel subtypes}

The evident selective coupling between D2-like receptors and N-type calcium channels raises another question how the effect of deletion of D2R is. To address the question, contribution of calcium channel subtypes in the GABAergic transmission onto striatal cholinergic interneurons was examined using D2R KO mice. IPSCs were evoked in striatal cholinergic interneurons by focal stimulation at $0.2 \mathrm{~Hz}$ at the holding potential of $-60 \mathrm{mV}$. Figure $5 \mathrm{Aa}$ shows the effect of an N-type calcium channel blocker, $\omega$-CgTX (3 $\mu \mathrm{M})$ on the amplitude of the evoked IPSCs in a wild type mouse. IPSCs were gradually suppressed by bath application of $\omega$-CgTX and the effect reached the steady state in 5-10 min. IPSCs were inhibited by $\omega$-CgTX by $58.6 \pm 1.97 \%$ (n=6, Fig. 5C) in wild type mice. As shown in Figure 5Aa, additional application of a P/Q-type calcium channel blocker, $\omega$-Aga-TK (200 nM) after $\omega$-CgTX-induced effect had reached steady state further suppressed the IPSCs. The inhibition of IPSCs by additional application of $\omega$-Aga-TK was $96.4 \pm 0.57 \%$ of the control $(n=4$, not 
shown). Figure 5Ba shows the effect of $\omega$-Aga-TK (200 nM) and additional application of $\omega$-CgTX $(3 \mu \mathrm{M})$ on the IPSCs. The inhibitory effect of $\omega$-Aga-TK was $76.2 \pm 2.96 \%(n=7$,

Fig. 5D) of the control in wild type mice. Additional application of a $\omega$-CgTX after $\omega$-Aga-TK-induced effect had reached steady state suppressed the IPSCs by $98.1 \pm 1.40 \%$ (n=7, not shown).

Figure 5Ab shows the effect of $\omega$-CgTX and additional application of $\omega$-Aga-TK on the IPSCs in a D2R KO mouse. Inhibition by $\omega$-CgTX was smaller in D2R KO than in wild type mice. The inhibitory effect of $\omega$-CgTX in these mice was $26.4 \pm 5.75 \%$ (n=6, Fig. 5C), which was significantly $(\mathrm{P}<0.05)$ smaller than the value of wild type mice $(58.6 \pm 1.97 \%$, Fig. 5C).

On the other hand, the $\omega$-Aga-TK-induced inhibitory effect was significantly larger in D2R KO mice (87.2. $\pm 0.94 \%, n=5)$ than in wild type mice $(76.2 \pm 2.96 \%, n=7)$, as shown in Figures 5B and D $(\mathrm{P}<0.05)$.

\section{Developmental changes in $\omega$-CgTX-induced effect in wild type and D2R KO mice}

It has been reported, in the striatum of rats, that $\omega$-CgTX-induced inhibition of IPSCs declines with age in the same GABAergic synapse as in the present study (Momiyama, 2003). Therefore, developmental changes were elucidated in $\omega$-CgTX-induced inhibition of IPSCs in D2R KO as well as wild type mice. The present study has so far used wild type and D2R KO mice of postnatal days between 20 and 23 days (P20-23). In the following experiments, 
$\omega$-CgTX-induced inhibition of IPSCs was examined using P35-44 mice (adult group, wild type and D2R KO) to compare the values obtained in the above experiments using the young (P20-23) group mice.

In the adult wild type mice, $\omega$-CgTX-induced inhibition of IPSCs was $18.2 \pm 3.21 \%$ ( $\mathrm{n}=7$, Fig. $5 \mathrm{E})$, that was significantly $(\mathrm{P}<0.05)$ smaller than that in the young group $(58.6 \pm$ $1.97 \%$, n=6, Fig. 5E). The finding was similar developmental decline to that observed in rats (Momiyama, 2003). On the other hand, in D2R KO mice, $\omega$-CgTX-induced inhibition of IPSCs was $26.9 \pm 2.55 \%$ (n=6, Fig. 5E), that was not significantly $(\mathrm{P}>0.05)$ different from that in young D2R KO mice (26.4 $\pm 5.75 \%$, n=6, Fig. 5E).

\section{DISCUSSION}

By means of D2R KO mice, the present study has revealed a physiological role of D2R in the regulation of GABAergic synaptic transmission onto striatal cholinergic interneurons, as well as the tight coupling between D2R and N-type calcium channels in the regulation of GABA release.

The present study has focused only on inhibitory transmission onto cholinergic interneurons. Although the changes in motor activities may be directly affected by the modulation of medium spiny neurons (MSNs) which express either D1R or D2R, 
dopamine-induced effect on the activity of medium spiny neurons reported by previous studies are still ambiguous and multifaceted (Surmeier et al., 2009). On the other hand, dopamine receptor-mediated effects on striatal cholinergic interneurons reported to date have been comprehensive; D5 receptor-mediated enhancement of Zn2+-sensitive GABA $\mathrm{A}_{\mathrm{A}}$ currents (Yan and Surmeier, 1997), D1-like receptor-mediated depolarization of the membrane (Aosaki et al., 1998), presynaptic D2-like receptor-mediated inhibition of GABA release onto cholinergic interneurons (Pisani et al., 2000; Momiyama and Koga. 2001), and D2-receptor-mediated reduction of autonomous activity through modulation of voltage-dependent $\mathrm{Na}+$ channels (Maurice et al., 2004) . In terms of modulation of firing, agonist activation of D2-like receptors has been reported to reduce firing frequency of most of cholinergic interneurons (Maurice et al., 2004; Wang et al., 2013). Furthermore, receptor subtypes involved in the presynaptic and postsynaptic actions of dopamine has been reported using DA receptor mutant mice (Centonze et al., 2003). In addition, activities of cholinergic interneurons are indirectly affected by dopamine-dependent modulation of MSN activity. For example, substance P released from D1R expressing MSNs has been shown to affect ACh release (Arenas et al., 1991). Therefore, there should be a rationale for relating activities of striatal cholinergic interneurons to motor activities.

The present electrophysiological experiments showed frequency-dependent suppression of IPSCs was present in striatal cholinergic interneurons of wild type mice, and this suppression 
was decreased in D2R KO mice. Previous studies have reported DA or quinpirole, a D2-like receptor agonist, inhibits IPSCs by presynaptic mechanisms (Pisani et al., 2000; Momiyama and Koga, 2001). Therefore, the present findings suggest that intrinsic DA activates D2R and thereby inhibits GABA release, demonstrating a physiological role for DA. The manner of termination of dopaminergic axons from substantia nigra pars compacta is quite different from that of GABAergic terminals in the striatum (Freund et al., 1984; Kubota et al., 1987); the former does not form strict synaptic structures observed with fast excitatory or inhibitory synapses. Therefore, DA-induced modulatory effects are expected to be prominent under unusual conditions. Generally, trains of stimuli are required to induce DA-mediated synaptic responses (Beckstead et al., 2004). Frequency-dependent suppression of synaptic currents has been reported at climbing fibre-Purkinje cell synapses, and several mechanisms have been proposed (Silver et al., 1998). The attenuation in frequency-dependent suppression of inhibitory inputs onto cholinergic interneurons observed in D2R KO mice would imply that cholinergic interneurons receive more inhibition overall in D2R KO mice (Fig. 3A and 3B). It remains to be elucidated how this enhanced inhibition of cholinergic interneurons in D2R KO mice results in a hypoactive phenotype (Yamaguchi et al., 1996). Also in the striatal GABAergic synapses onto cholinergic interneurons, there should be unknown mechanisms other than D2-like receptor-mediated inhibition, including those mediated by some other monoamines or peptides. 
In the present study, contribution of N-type calcium channels in the GABAergic transmission onto striatal cholinergic interneurons was significantly decreased in D2R KO mice, whereas P/Q-type calcium channel contribution increased. This seems functionally reasonable, since our previous study has shown a selective coupling between D2-like receptors and $\mathrm{N}$-type calcium channels in the modulation of GABA release onto cholinergic interneurons (Momiyama and Koga, 2001, Fig.5A). Deletion of D2R could downregulate the coupled downstream effectors. Actually, it has been demonstrated, using co-immunoprecipitation and pull down assays, that D2R and N-type calcium channels form physical signaling complex, and that $\mathrm{D} 2 \mathrm{R}$ regulate $\mathrm{N}$-type calcium channel trafficking (Kisilevsky and Zamponi, 2008), suggesting that absence of D2R in D2R KO mice may aberrantly affect the trafficking of N-type calcium channels to the membrane, thereby reducing their contribution to inhibitory transmission. The coupling between D2R and N-type calcium channels has been further suggested in the present study, since the developmental changes was not observed in the contribution of N-type calcium channels in GABAergic transmission onto striatal cholinergic interneurons in D2R $\mathrm{KO}$ mice, whereas $\omega$-CgTX-induced inhibition was significantly decreased in adult wild type mice compared to young mice, similar to the results in rats (Momiyama, 2003). These findings suggest that such a developmental change could occur only when the coupling partners are normally present in the synapse. 
The present findings using cell-attached recording have confirmed the notion that DA could modulate the overall firing of striatal cholinergic neurons through the action on D2-like receptors. In addition, frequency-dependent suppression of IPSCs suggests that D2R located on GABAergic presynaptic terminals could have a considerable role in the regulation of neuronal activity, as suggested by the previous study (Momiyama and Koga, 2001). Although suppression of inhibitory transmission onto striatal cholinergic neurons by the activation of presynaptic D2R could result in the excitation of cholinergic neurons and therefore may lead to the enhanced ACh release in the striatum, the present data using cell-attached recording has shown high frequency stimulus-induced suppression of firing rate, consistent with previous studies showing D2-like receptor agonist-induced inhibition of the firing of striatal cholinergic interneurons by modulation of voltage-dependent $\mathrm{Na}^{+}$channels (Maurice et al., 2004; Wang et al., 2013). It has also been shown that D2R activation leads to a slowing of pacemaker discharge (Maurice et al., 2004). Previous neurochemical studies have also reported a real physiological phenomenon that D2-like receptor agonists reduce ACh release (for review, Di Chiara et al., 1994). There may be other unknown mechanisms that participate in the net modulation of neuronal activities of striatal cholinergic interneurons.

GABAergic inputs to striatal cholinergic neurons are likely to be originating from axon collaterals of striatal medium spiny neurons (Bolam et al., 1986; Martone et al., 1992) or possibly from GABAergic interneurons (Bennett and Wilson, 1998; Koós and Tepper, 1999). 
The projection pattern, DA receptor subtypes and neurochemical markers of medium spiny neurons have been reported to be heterogeneous (Gerfen, 2000 and references therein). To date, the quantitative anatomical information for the identification of GABAergic inputs to striatal cholinergic neurons is not yet available. It also remains to be seen the precise subcellular immunocytochemical localization of identified DA receptor subtypes expressed in medium spiny neurons, which could be revealed at the electron microscopy level by the use of specific antibodies for DA receptor subtypes.

\section{REFERENCES}

Aosaki T, Kiuchi, K, Kawaguchi Y (1998) Dopamine D1-like receptor activation excites rat striatal large aspiny neurons in vitro. J Neurosci 15:5180-5190.

Arenas E, Alberch J, Perez-Navarro E, Solsona C, Marsal J (1991) Neurokinin receptors differentially mediate endonenous acetylcholine release evoked by tachykinins in the neostriatum. J. Neurosci 11:2332-2338.

Beckstead MJ, Grandy DK, Wickman K, Williams JT (2004) Vesicular dopamine release elicits an inhibitory postsynaptic current in midbrain dopamine neurons. Neuron 42:939-946. 
Bennett BD, Wilson CJ (1998) Synaptic regulation of action potential timing in neostriatal cholinergic interneurons. J Neurosci 15:8539-8549.

Bolam JP, Ingham CA, Izzo PN, Levey AI, Rye DB, Smith AD, Wainer BH (1986) Substance P-containing terminals in synaptic contact with cholinergic neurons in the neostriatum and basal forebrain: a double immunocytochemical study in the rat. Brain Res 397:279-289.

Calabresi P, Picconi B, Tozzi A, Di Filippo M (2007) Dopamine-mediated regulation of corticostriatal synaptic plasticity. Trends Neurosci 30:211-219.

Centonze DC, Grande C, Usiello A, Gubellini P, Erbs E, Martin AB, Pisani A, Tognazzi N, Bernardi G, Moratalla R, Borrelli E, Calabresi P (2003) Receptor subtypes involved in the presynaptic and postsynaptic actions of dopamine on striatal interneurons. J Neurosci 23:6245-6254.

Crag SJ (2006) Meaningful silences: how dopamine listens to Ach pause. Trends Neurosci 29:125-131.

Di Chiara G, Morelli M, Consolo S (1994). Modulatory functions of neurotransmitters in the striatum: ACh/dopamine/NMDA interactions. Trends in Neurosci 17:228-233.

Freund TF, Powell JF, Smith AD (1984) Tyrosine hydroxylase-immunoreactive boutons in synaptic contact with identified striatonigral neurons, with particular reference to dendritic spines. Neuroscience 13:1189-1215. 
Gerfen CD (2000) Molecular effects of dopamine on striatal-projection pathways.

Trends Neurosci. Suppl S64-70.

Govindaiah G, Wang Y, Cox CL (2010) Substance P selectively modulates GABA receptor-mediated synaptic transmission in striatal cholinergic interneurons. Neuropharmacology 58:413-422.

Jiang Z-G, North RA (1991) Membrane properties and synaptic responses of rat striatal neurones in vitro. J Physiol (Lond) 443:533-553.

Kawaguchi Y (1992) Large aspiny cells in the matrix of the rat neostriatum in vitro: physiological identification, relation to the compartments and excitatory postsynaptic currents. J. Neurophysiol 67:1669-1682.

Kawaguchi Y, Wilson CJ, Augood SJ, Emson PC (1995) Striatal interneurones: chemical, physiological and morphological characterization. Trends Neurosci 18:527-535.

Kisilevsky AE, Zamponi GW (2008) D2 dopamine receptors interact with N-type calcium channels and regulate channel surface expression levels. Channels 2:1-8.

Koós T, Tepper JM (1999) Inhibitory control of neostriatal projection neurons by GABAergic interneurons. Nat. Neurosci 2:467-472.

Kreitzer AC, Malenka RC (2008) Striatal plasticity and basal ganglia circuit function. Neuron 60:543-554.

Kubota Y, Inagaki S, Shimada S, Kito S, Eckenstein F, Tohyama M (1987) Neostriatal 
cholinergic neurons receive direct synaptic inputs from dopaminergic axons. Brain Res 413:179-184.

Martone ME, Armstrong DM, Young SJ, Groves PM (1992) Ultrastructural examination of enkephalin and substance $\mathrm{P}$ input to cholinergic neurons within the rat neostriatum. Brain Res 594:253-262.

Maurice N, Mercer J, Chan CS, Hernandez-Lopez S, Held J, Tkatch T, Surmeier DJ (2004) D2 dopamine receptor-mediated modulation of voltage-dependent $\mathrm{Na}^{+}$channels reduce autonomous activity in striatal cholinergic interneurons. J Neurosci 24:10289-10301.

Momiyama T (2003) Parallel decrease in omega-conotoxin-sensitive transmission and dopamine-induced inhibition at the striatal synapse of developing rats. J Physiol (Lond) 546:483-490

Momiyama T, Koga E (2001) Dopamine D2-like receptors selectively block N-type $\mathrm{Ca}^{2+}$ channels to reduce GABA release onto rat striatal cholinergic interneurones. J Physiol (Lond) 533:479-492.

Pisani A, Bernardi G, Ding J, Surmeier DJ (2007) Re-emergence of striatal cholinergic interneurons in movement disorders. Trends Neurosci 30:545-553.

Pisani A, Bonsi P, Centonze D, Calabresi P, Bernardi G (2000) Activation of D2-like dopamine receptors reduces synaptic inputs to striatal cholinergic interneurons. 


\section{J. Neurosci 20(7):RC69.}

Silver RA, Momiyama A, Cull-Candy SG (1998) Locus of frequency-dependent depression identified with multiple-probability fluctuation analysis at rat climbing fibre-Purkinje cell synapses. J Physiol (Lond) 510:881-902.

Surmeier DJ, Ding J, Day M, Wang Z, Shen W (2007) D1 and D2 dopamine-receptor modulation of striatal glutamatergic signaling in striatal medium spiny neurons.

Trends Neurosci 30:228-235.

Surmeier DJ, Plotokin J, Shen W (2009) Dopamine and synaptic plasticity in dorsal striatal circuits controlling action selection. Curr Opin Neurobiol 19:621-628.

Wang W, Darvas M, Storey GP, Bamford IJ, Gibbs JT, Palmiter RD, Bamford NS (2013). Acetylcholine encodes long-lasting presynaptic plasticity at glutamatergic synapses in the dorsal striatum after repeated amphetamine exposure. J Neurosci 33:10405-10426.

Yamaguchi H, Aiba A, Nakamura K, Nakao K, Sakagami H, Goto K, Kondo H, Katsuki M (1996) Dopamine D2 receptor plays a critical role in cell proliferation and proopiomelanocortin expression in the pituitary. Genes Cells 1:253-268.

Yan Z, Surmeier DJ (1997) $\mathrm{D}_{5}$ dopamine receptors enhance $\mathrm{Zn}^{2+}$-sensitive GABA ${ }_{\mathrm{A}}$ currents in striatal cholinergic interneurons through a PKA/PP1 cascade. Neuron 19:1115-1126.

\section{ACKNOWLEDGEMENTS}


The authors are grateful to J.A. Sim for valuable comments on the data and manuscript, and to M. Kagata for technical assistance. This work was supported by a Grant-in-Aid for Scientific Research from the Ministry of Education, Culture, Sports, Science and Technology of Japan (no. 20019030 and 21500374 to TM, and no. 19500334 and 22500343 to TS), and Core Research for Evolutional Science and Technology (CREST) from Japan Science and Technology Corporation, the NIBB Cooperative Research Program (10-336) and the Collaborative Research Project (no. 2011-2221) of the Brain Research Institute, Niigata University.

\section{Legends for Figures}

\section{Fig. 1. Striatal cholinergic interneurons in wild type mice}

A, A striatal cholinergic interneuron in a brain slice obtained from a wild type mouse (postnatal day 20) viewed under IR-DIC microscopy. The recording pipette is attached to the surface of the neuron, and the stimulating electrode is placed close to the recorded neuron.

The slice was $300 \mu \mathrm{m}$ in thickness. $\boldsymbol{B}$, Membrane potentials (above) recorded from another striatal cholinergic interneuron in response to hyperpolarizing current pulses (below) applied intracellularly through $\mathrm{Cs}^{+}$-filled electrodes. Voltage sags during hyperpolarizing current pulses, characteristic to striatal cholinergic neurons, were identified. $C$, GABAergic inhibitory postsynaptic currents (IPSCs) recorded in a striatal cholinergic neuron. Each point in the time 
course plot represents the amplitude of an individual IPSC evoked at $0.2 \mathrm{~Hz}$ (every 5s) in the

presence of CNQX $(5 \mu \mathrm{M})$, D-AP5 $(25 \mu \mathrm{M})$ and strychnine $(0.5 \mu \mathrm{M})$ through a $\mathrm{Cs}^{+}$-filled electrode. The holding potential was $-60 \mathrm{mV}$. Superimposed traces on the right are averages of 20 consecutive IPSCs during the indicated periods. IPSCs were blocked by bath-applied bicuculline $(10 \mu \mathrm{M})$.

\section{Fig. 2. Selective coupling of D2-like receptors with $\mathrm{N}$-type calcium channels}

$\boldsymbol{A}$, Time course of effects of quinpirole $(\mathrm{Q}, 30 \mu \mathrm{M})$ on IPSCs before and after application of $\omega$-CgTX $(3 \mu \mathrm{M})$ in a wild type mouse. Amplitudes of IPSCs evoked at $0.2 \mathrm{~Hz}$ are plotted against time at the holding potential of $-60 \mathrm{mV}$ with CsCl-based internal solution. Quinpirole-induced inhibition of IPSCs was occluded in the presence of $\omega$-CgTX. Superimposed traces on the right are averages of 20 consecutive IPSCs during the indicated

periods. $\quad \boldsymbol{B}$, Lack of quinpirole-induced effect in a D2R KO mouse. Superimposed traces on the right are averages of 20 consecutive IPSCs during the indicated periods. $\boldsymbol{C}$, Summarized histograms from pooled data showing the effects in $\boldsymbol{A}$ and $\boldsymbol{B}$. Percent inhibition of IPSCs in wild type mice by quinpirole, quinpirole in the presence of $\omega$-CgTX, and quinpirole in D2R KO mice was, $32.9 \pm 2.24 \%(n=4), 2.07 \pm 0.53 \%(n=4)$, and $3.28 \pm 1.38 \%(n=6)$, respectively. 
Fig. 3. Frequency-dependent suppression of IPSCs in striatal cholinergic interneurons

$\boldsymbol{A}$, IPSCs were evoked in striatal cholinergic interneurons in the presence of CNQX (5 $\mu \mathrm{M})$, D-AP5 $(25 \mu \mathrm{M})$ and strychnine $(0.5 \mu \mathrm{M})$ at the holding potential of $-60 \mathrm{mV}$. The patch pipette contained a CsCl-based internal solution. Superimposed traces are averages of 10 consecutive IPSCs evoked in a wild type (WT) mouse (left) and a D2R KO mouse (right). The averages were obtained after the IPSC amplitude had reached the steady state after the stimulus onset of each frequency. Each stimulus frequency is indicated on the left of traces evoked in the wild type mouse. Stimulus artifacts have been omitted. Note the lack of suppression of IPSCs in the D2R KO mouse. $\boldsymbol{B}$, Summarized plots showing the frequency dependent suppression of IPSC as a fraction of amplitude at $0.2 \mathrm{~Hz}$ in WT (open circles), WT in the presence of sulpiride (10 $\mu \mathrm{M}$, open squares) and D2R KO mice (closed circles). The difference between with and without sulpiride in WT was significant $(\mathrm{P}<0.05)$ at 5 and $10 \mathrm{~Hz}\left({ }^{\#}\right)$. The suppression was significantly $(\mathrm{P}<0.05)$ reduced in $\mathrm{D} 2 \mathrm{R} \mathrm{KO}$ mice at each of the corresponding stimulus frequency $(*)$. Each point shows mean with S.E.M. derived from 5-16 cells.

Fig. 4. Effects of high frequency stimulation of the firing of cholinergic interneurons

$\boldsymbol{A}$, Cell-attached recording of spontaneous action potential firing in a cholinergic interneuron of a wild type mouse (WT, P23) under control condition (Control), just after $10 \mathrm{~Hz}$ stimulation for $10 \mathrm{~s}(10 \mathrm{~Hz})$, and after $10 \mathrm{~Hz}$ stimulation for $10 \mathrm{~s}$ in the presence of sulpiride 
(10 $\mu \mathrm{M}, 10 \mathrm{~Hz}$ in sulpiride). Firing was inhibited by $10 \mathrm{~Hz}$ stimulation and the inhibition was antagonized by sulpiride. $\boldsymbol{B}$, Cell-attached recording of in a cholinergic interneuron of a D2R KO mouse (D2R KO, P23) under control condition (Control) and just after $10 \mathrm{~Hz}$ stimulation for $10 \mathrm{~s}(10 \mathrm{~Hz})$. The stimulation had no effect in the D2R KO mouse. $\boldsymbol{C}$, Summarized histograms showing the 5 and $10 \mathrm{~Hz}$ ( 5 and 10 below the hatched histograms, respectively) stimulation-induced inhibition of the action potential firing, antagonism by sulpiride, and lack of the effect in $\mathrm{D} 2 \mathrm{R}$ KO mice. *, $\mathrm{P}<0.05$ with paired $t$-test compared with the firing rate in control condition (white histogram).

Fig. 5. Effects of $\omega$-CgTX and $\omega$-Aga-TK on the IPSCs evoked in striatal cholinergic interneurons

$\boldsymbol{A}$, Time course of inhibitory effect of $\omega$-CgTX $(3 \mu \mathrm{M})$ and subsequent application of $\omega$-Aga-TK (200 nM) on the IPSCs in a wild type (WT, a) and a D2R KO mouse (D2KO, b). Toxins were bath applied during the indicated periods. Each point in the time course plot represents the amplitude of an individual IPSC evoked at $0.2 \mathrm{~Hz}$ (every 5s) in the presence of CNQX (5 $\mu \mathrm{M})$, D-AP5 (25 $\mu \mathrm{M})$ and strychnine $(0.5 \mu \mathrm{M})$ with CsCl-based internal solution. The holding potential was $-60 \mathrm{mV}$. Superimposed traces on the right are averages of 20 consecutive IPSCs during the indicated periods. $\boldsymbol{B}$, Time course of the effect of $\omega$-Aga-TK and subsequent application of $\omega$-CgTX on the IPSCs in a WT (a) and a D2R KO mouse (b) $\boldsymbol{C}$, 
Summarized histograms showing the inhibitory effect of $\omega$-CgTX on WT and D2R KO mice. Numbers of cells tested are indicated in parentheses. The effect of $\omega$-CgTX was significantly smaller in D2R KO mice than in wild type mice $(* \mathrm{P}<0.05)$. $\boldsymbol{D}$, Summarized histograms showing the inhibitory effect of $\omega$-Aga-TK on WT and D2R KO mice. Effect of $\omega$-Aga-TK was significantly $(\mathrm{P}<0.05)$ larger in $\mathrm{D} 2 \mathrm{R}$ KO mice than in WT mice $(*)$. $\boldsymbol{E}$, Developmental changes in $\omega$-CgTX-induced effect in WT and D2R KO mice. The value of WT at P20-23 (young) is identical in Fig. 5C. The $\omega$-CgTX-induced inhibition of IPSCs was significantly $(\mathrm{P}<0.05$, *) smaller at $\mathrm{P} 35-44$ (adult) than young group. On the other hand, the $\omega$-CgTX-induced inhibition was not significantly $(\mathrm{P}>0.05)$ different between young and adult D2R KO mice. 
Figure 1
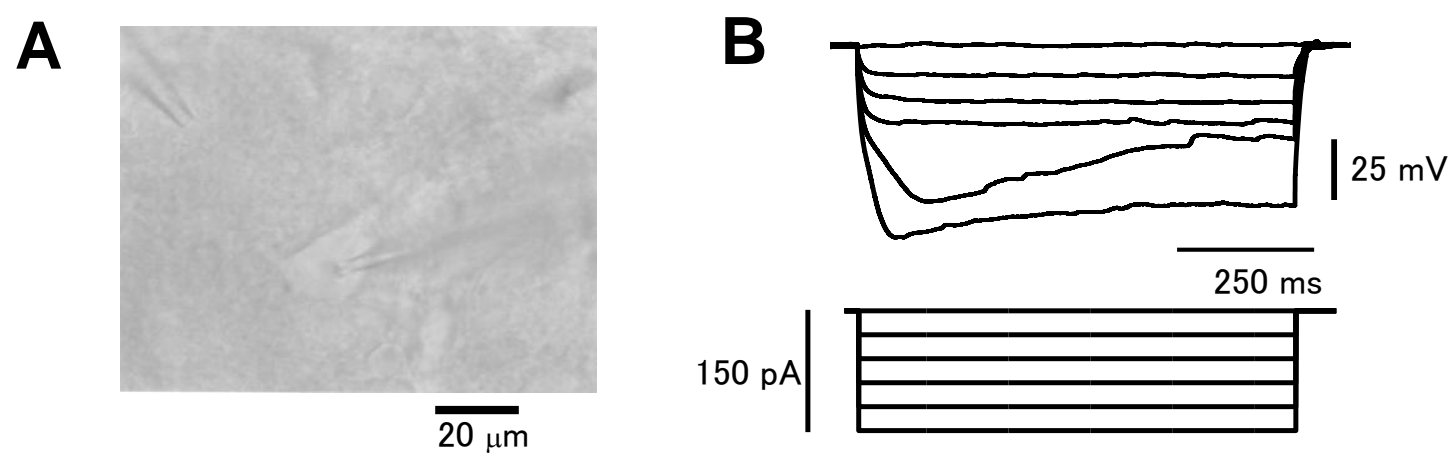

C
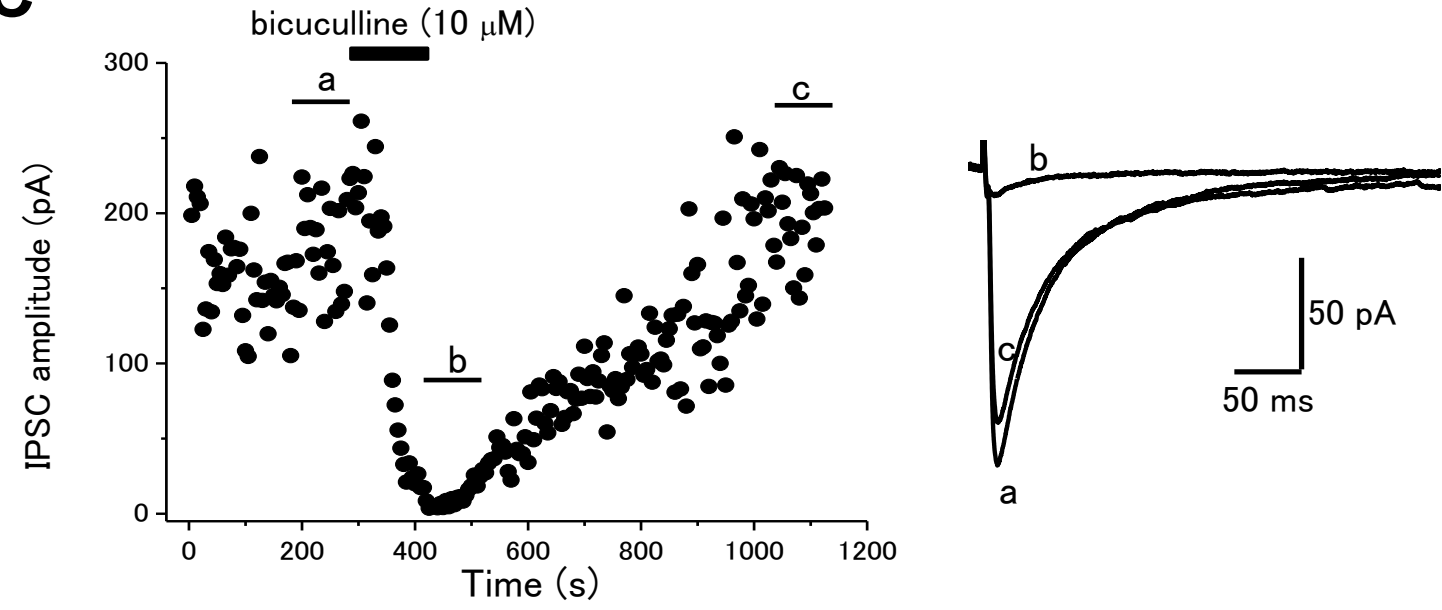
Figure 2

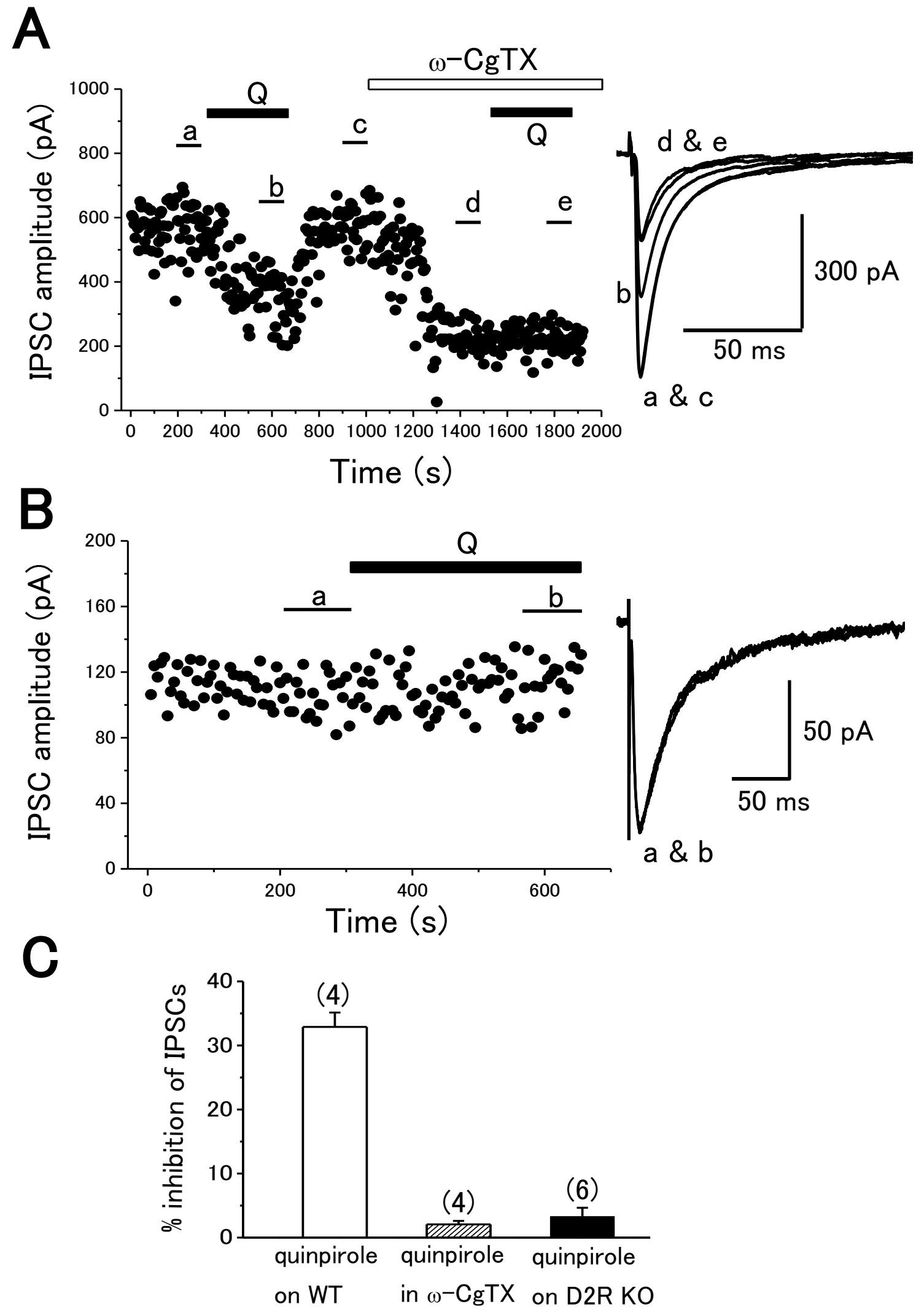


Figure 3

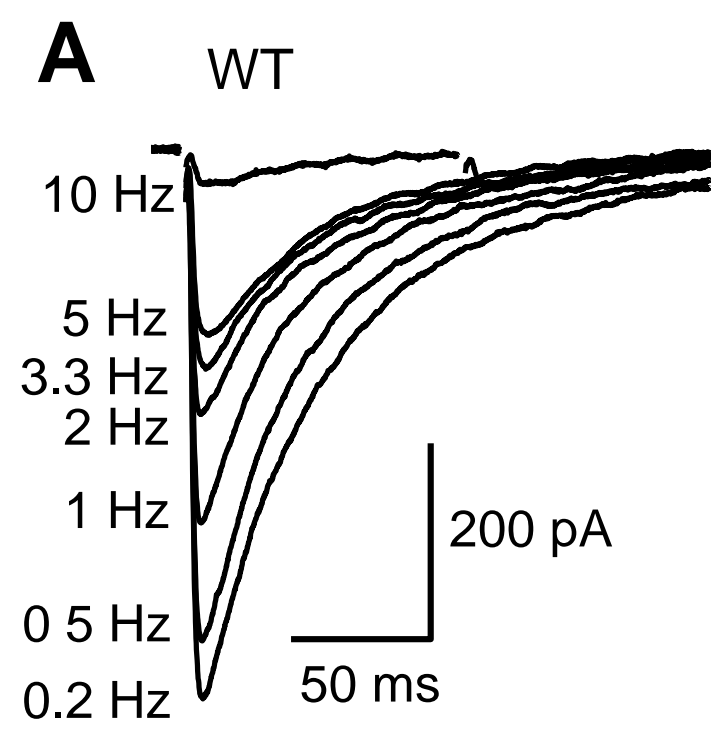

D2R KO
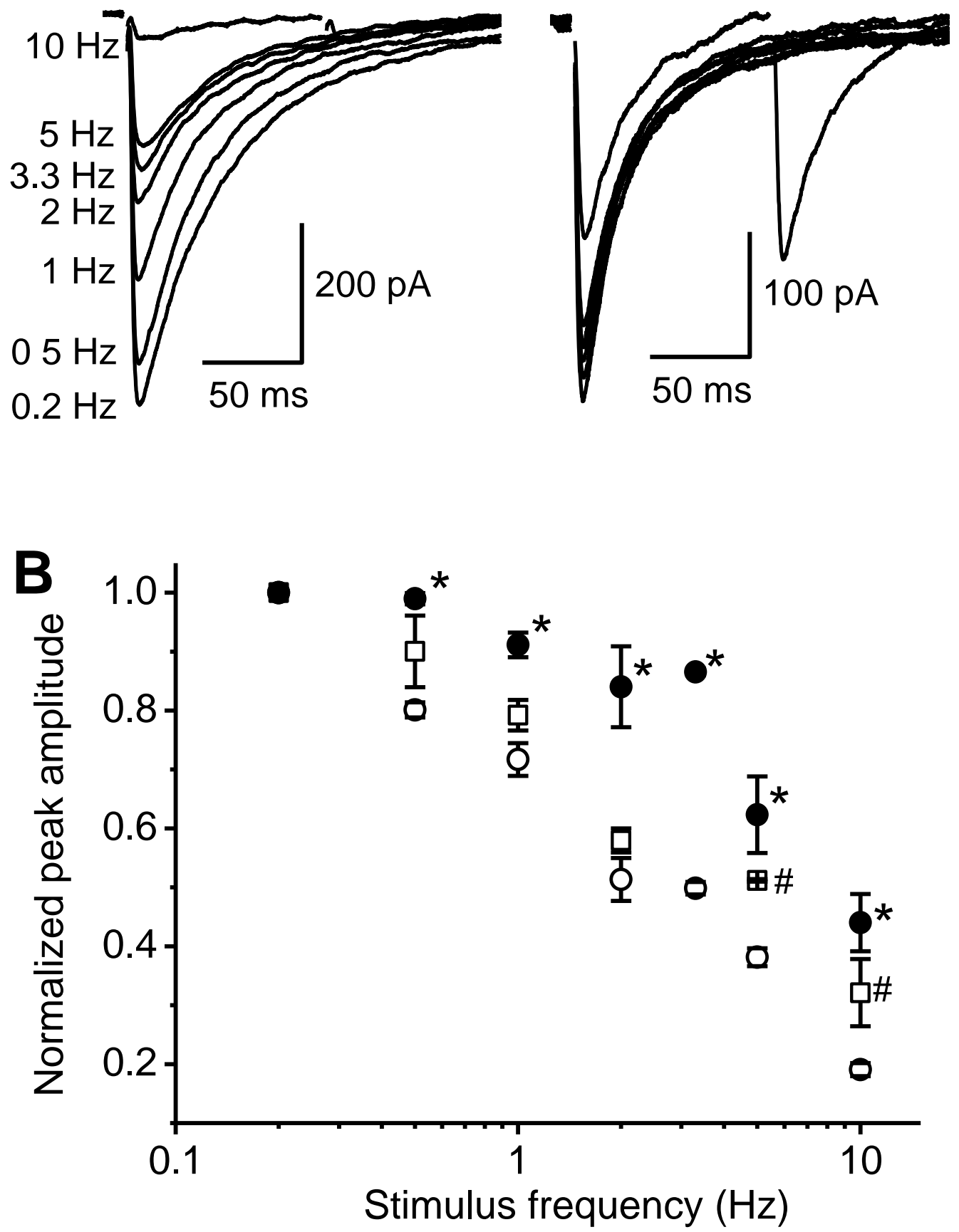
Figure 4

A $W T$

Control

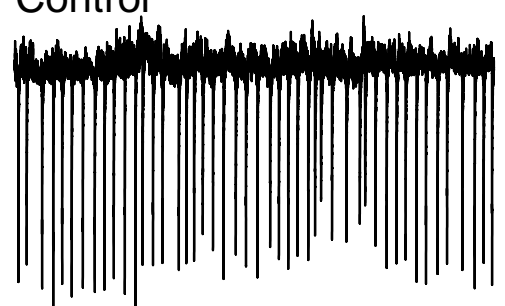

$10 \mathrm{~Hz}$

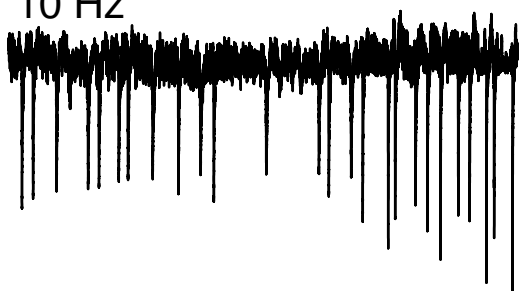

$10 \mathrm{~Hz}$ in sulpiride

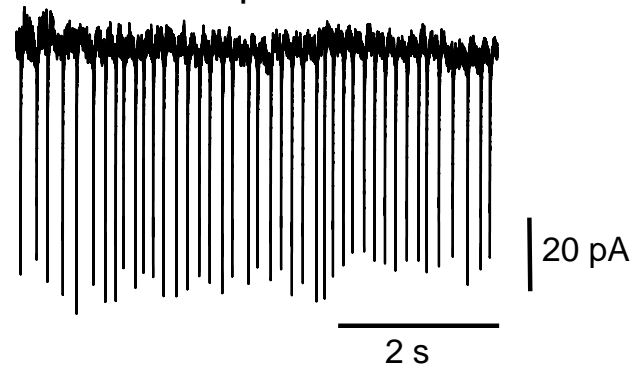

B D2R KO

Control

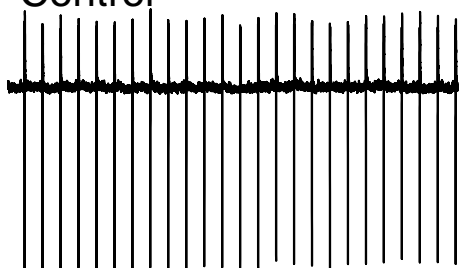

$10 \mathrm{~Hz}$

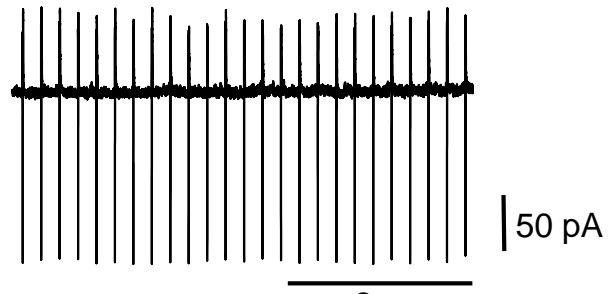

C

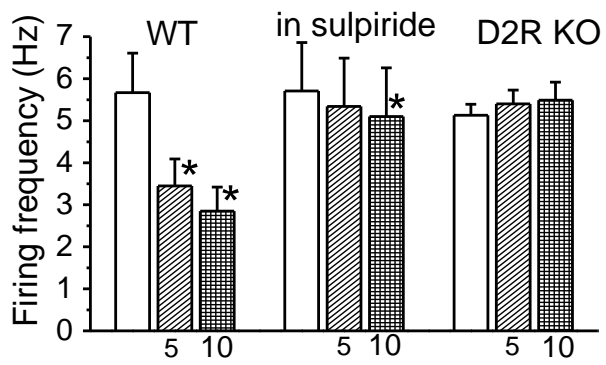




\section{Figure 5}
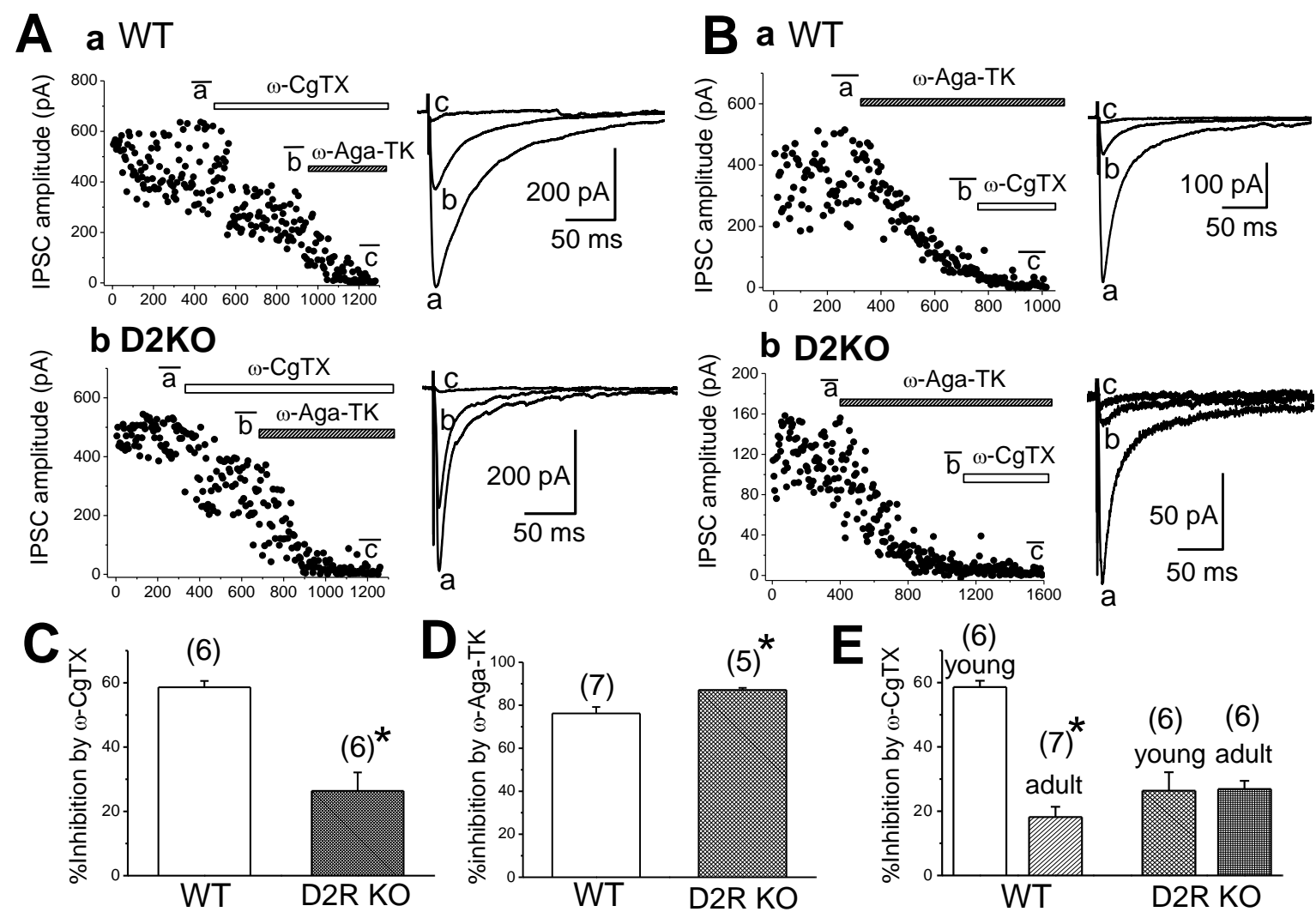

E.

(6)

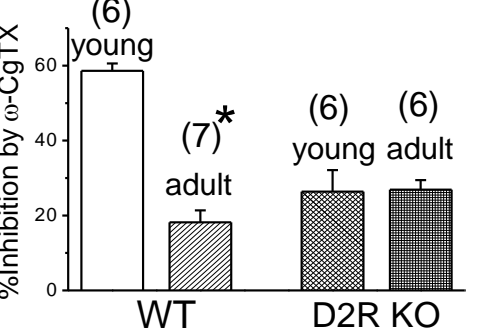

